\title{
Correlation between subsurface high-salinity water in the northern South China Sea and the North Equatorial Current-Kuroshio circulation system from HYCOM simulations
}

\author{
A. Wang ${ }^{1,2}$, Y. Du ${ }^{1}$, W. Zhuang ${ }^{1}$, and Y. Qi ${ }^{1}$ \\ ${ }^{1}$ State Key Laboratory of Tropical Oceanography (LTO), South China Sea Institute of Oceanology, \\ Chinese Academy of Sciences, Guangzhou 510301, China \\ ${ }^{2}$ University of Chinese Academy of Sciences, Beijing 100049, China \\ Correspondence to: Y. Du (duyan@scsio.ac.cn)
}

Received: 31 August 2014 - Published in Ocean Sci. Discuss.: 28 October 2014

Revised: 5 February 2015 - Accepted: 16 March 2015 - Published: 1 April 2015

\begin{abstract}
The North Pacific Tropical Water (NPTW), characterized by subsurface high salinity, is observed in the South China Sea (SCS) and is often used as an indicator of the water intrusion from the northwestern Pacific into the SCS. Based on the assimilation product from a global high-resolution Hybrid Coordinate Ocean Model (HYCOM) from 2008 through 2013, this study investigates the seasonal variability of subsurface high-salinity water (SHSW) in the northern SCS and its relationship with the North Equatorial Current-Kuroshio circulation system. Results show that the obvious seasonal variability of the SHSW appears at about $100-200 \mathrm{~m}$ in depth. It extends as far west as southeast of Hainan, reaching its volume maximum (minimum) in January (May). The seasonal variance contribution (seasonal variance accounting for the entire variance) is 0.38 in the period we considered, albeit with significant annual variance in other years. Further analysis shows that the changes in high-salinity water volume are highly correlated with the shift in the North Equatorial Current bifurcation latitude (NECBL), which reaches its northernmost point in December and its southernmost point in May. Due to the large-scale wind changes in the Pacific, the Luzon Strait transport (LST) weakens (strengthens) when the NECBL shifts to the south (north) during summer (winter), which results in the reduced (enhanced) SHSW intrusion from the northwestern Pacific into the northern SCS. It is also found that, on a seasonal timescale, the Kuroshio transport (KT) does not vary in phase with NECBL, LST and
\end{abstract}

SHSW, indicating that the KT changes are probably not the governing factor for the seasonal variability of SHSW in the northern SCS.

\section{Introduction}

The South China Sea (SCS) is the largest marginal sea with fascinating physical processes in the northwestern Pacific. There exists subsurface high-salinity water (SHSW) in the northern SCS whose variations attract much attention (e.g., Wang and Chern, 1997; Qu et al., 1999, 2000; Liu et al., 2010). The SHSW is often used as the passive tracer of the North Pacific Tropical Water (NPTW) (Qu et al., 1999; Li and Wang, 2012) because of its unique water mass properties. The distribution and variation of the SHSW in the northern SCS exert significant influence on the ocean stratification and the upper circulation. The Luzon Strait (LS), located between Taiwan and Luzon, is the only deep passage connecting the SCS and the western Pacific with a maximum depth deeper than $2200 \mathrm{~m}$. It is also the most influential passage where the Kuroshio affects the SCS. Previous studies indicated that the water exchange through the LS plays an important role in conveying the impact of El Niño-Southern Oscillation (ENSO) on the SCS, modulating the SCS circulation, heat and salt budgets (Qu et al., 2004; Wang et al., 2006; Gordon et al., 2012). As one of the most impor- 

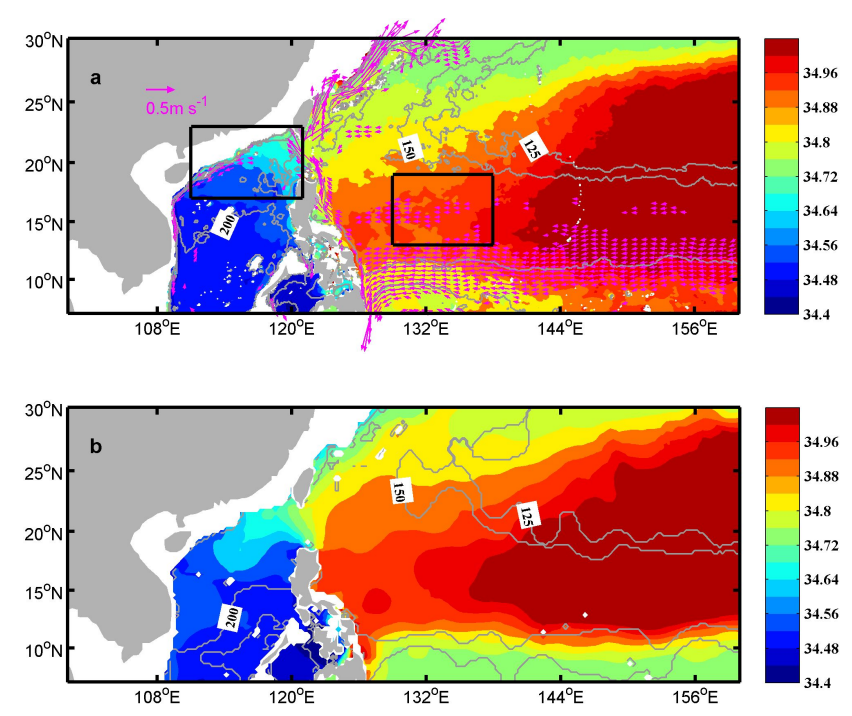

Figure 1. Distribution of the maximum salinity (color shading; PSU) and its depth (grey contours; m): (a) HYCOM; (b) WOA01. The boxes show the regions used for T-S analysis in Fig. 2. Subsurface currents (vectors, pink) larger than $0.1 \mathrm{~m} \mathrm{~s}^{-1}$ are superimposed.

tant tropical Pacific currents, the North Equatorial Current (NEC) flows westward across the Pacific basin and bifurcates into the northward Kuroshio and southward Mindanao Current when it encounters the coast of the Philippines (Nitani, 1972). As the northward-flowing Kuroshio reaches LS, it has various forms intruding into the SCS: (1) leaping across the LS to the north (Xu and Su, 1997; Su, 2001); (2) entering the SCS through a direct branch from the Kuroshio $(\mathrm{Pu}$ et al., 1992, 1993; Wang and Chern, 1996; Metzger and Hurlburt, 1996); (3) forming an anticyclonic loop current, which features an inflow in the southern LS and an outflow in the northern LS (Nitani, 1972; Farris and Wimbush, 1996; Li et al., 1996; Li and Liu, 1997); and (4) escaping into the internal SCS in the form of a high-frequency vortex (Wang et al., 1997; Li et al., 1998; Yuan et al., 2006). Through the water exchange in the LS, Pacific circulation can influence the SCS circulation directly.

As for seasonal variation, Wyrtki (1961) firstly mapped the winter and summer distributions of surface salinity in the SCS using in situ observations. He found that, in winter, there is a high-salinity water tongue intruding into the SCS through the LS and extending far into southern Vietnam along the continental shelf, while in summer, the highsalinity water tongue retreats. Based on the history of hydrologic observations, Shaw (1991) found that the Kuroshio front meanders into the northern SCS through the LS from June to September, but does not continue to invade far west of the LS. When the northeastern monsoon fully develops in late autumn to winter, water mass from the Pacific enters the SCS along the continental margin south of China and travels a distance of hundreds of kilometers into the SCS basin, significantly affecting the water mass characteristics in the SCS. From February to May, when the monsoon reverses its direction, the intrusion decays. Qu et al. (2000) further revealed that the Pacific subsurface high-salinity water intrudes into the SCS all year round through the LS, and has a pronounced semiannual signal with greater strength in winter and summer than in spring and autumn. From spring to autumn, the water intrusion from the Pacific is narrowly confined in the continental slope south of China. Only in winter, under the influence of the fully developed northeastern monsoon, can the intrusion be extended to the southern SCS. Drifting buoy observations also confirmed the obvious seasonal variability of upper Kuroshio intrusion, which is stronger in the winter (October-March) than in the summer (April-September) monsoon seasons (Centurioni et al., 2004).

However, due to the scarcity of in situ observations, the distribution and seasonal variations of the SHSW in the northern SCS are still lacking in quantitative investigations. With the development of numerical simulations in recent years, the numerical model has become a powerful tool to investigate the ocean circulation and water mass changes. In the present paper, we use a state-of-the-art oceanic model assimilation product to study the SHSW distribution and the mechanisms responsible for its seasonal variability.

The rest of the paper is organized as follows. In Sect. 2, we provide a brief description of the data and method used in this study. Section 3 presents the characteristics of the highsalinity water in the northern SCS and the potential forcing mechanism. A summary and discussion are given in Sect. 4.

\section{Data and method}

Our study is based on the Hybrid Coordinate Ocean Model (referred to as HYCOM) numerical assimilation product. Vertical coordinates in HYCOM are isopycnal in the open and stratified ocean, but smoothly transit to $z$ coordinates in the ocean mixed layer and sigma coordinates in coastal regions. The Navy Coupled Ocean Data Assimilation (NCODA) system was used to assimilate satellite altimeter observations and in situ measured data from XBT and Argo. HYCOM uses the standard Mercator coordinate with about $1 / 12^{\circ}$ horizontal resolution in tropical and subtropical areas. The model has 32 vertical layers. The daily model outputs during 2008-2013 are available at http://hycom.org and are used in this study.

The HYCOM product has been analyzed by a number of studies (e.g., Zhang and Du, 2012; Yuan et al., 2014; Zhang et al., 2010). Among others, Zhang and Du (2012) validated the reliability of the HYCOM simulation based on the World Ocean Atlas (WOA) observation data set and used the product to analyze the salinity changes in the northern Indian Ocean. Zhang et al. (2010) compared the HYCOM data with a cross-section observation in LS and found that the model 

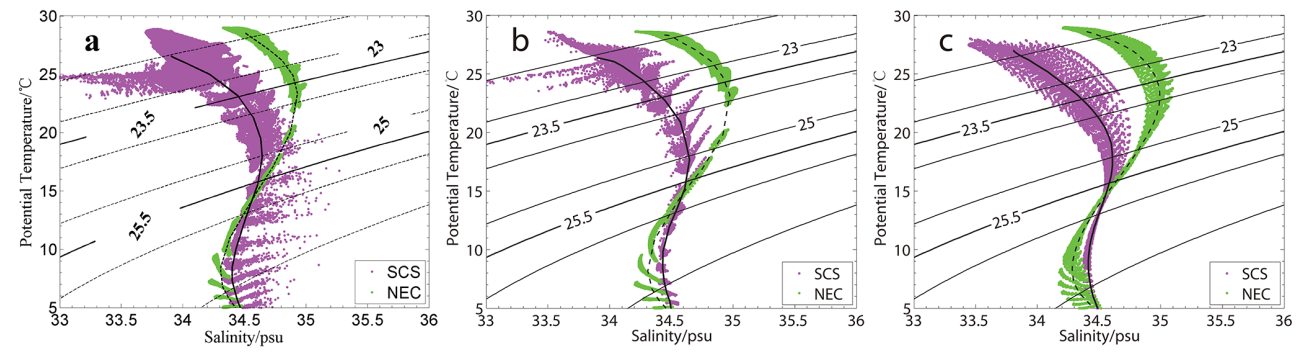

Figure 2. T-S diagram at the two black boxes in Fig. 1: (a) HYCOM; (b) WOA01; (c) MIMOC. Pink and green dots represent the selected waters in the SCS and Pacific, respectively.

reproduces the flow pattern in the vicinity of LS well. In this study, we also compare the modeled distribution of maximum salinity and its depth with the World Ocean Atlas 2001 (WOA01) observations in the northern Pacific. As shown in Fig. 1, the salinity distribution in the HYCOM simulation is generally similar to WOA01. Compared to the heavy spatial smoothing in WOA01, the model results show a more detailed and complex spatial structure. After Qu et al. (2000), we have also drawn the maps of salinity distribution on a $25.0 \sigma \theta$ surface that intersects NPTW using the HYCOM output (figure not shown). The patterns are generally similar to those shown in Qu et al. (2000), except that the highsalinity tongue is slightly weaker in the HYCOM simulations. We also computed the T-S diagram (Fig. 2) using the Monthly Isopycnal \& Mixed-layer Ocean Climatology (MIMOC) data (Schmidtko et al., 2013). These climatology data are based mostly on Argo Conductivity-Temperature-Depth (CTD) data, supplemented by shipboard and ice-tethered profiler CTD data, with resolution $0.5^{\circ} \times 0.5^{\circ}$ from $80^{\circ} \mathrm{S}$ to $90^{\circ} \mathrm{N}$. The data set is available at http://www.pmel.noaa.gov/ mimoc/.

To provide an overview of the dynamic effects in the subsurface layer, the averaged acceleration potential $(A=$ $\left.p_{0} \delta_{0}+\int_{\delta_{0}}^{\delta} p \mathrm{~d} \delta\right)$ in the subsurface layer is used. Acceleration potential is estimated by vertically integrating a specific volume anomaly $(p)$ from the reference level (Montgomery and Stroup, 1962; Reid, 1965),

$$
A=p_{0} \delta_{0}+\int_{\delta_{0}}^{\delta} p \mathrm{~d} \delta
$$

where $p$ is pressure, and $\delta_{0}$ and $p_{0}$ are specific volume anomaly and pressure at the reference level (1500 dbar), respectively. The geostrophic velocities along isopycnals are simply determined by lateral gradients of $A$,

$\left(u_{g}, v_{g}\right)=\left(-\frac{1}{f} \frac{\partial A}{\partial y}, \frac{1}{f} \frac{\partial A}{\partial x}\right)$,

where $f$ is the Coriolis parameter.
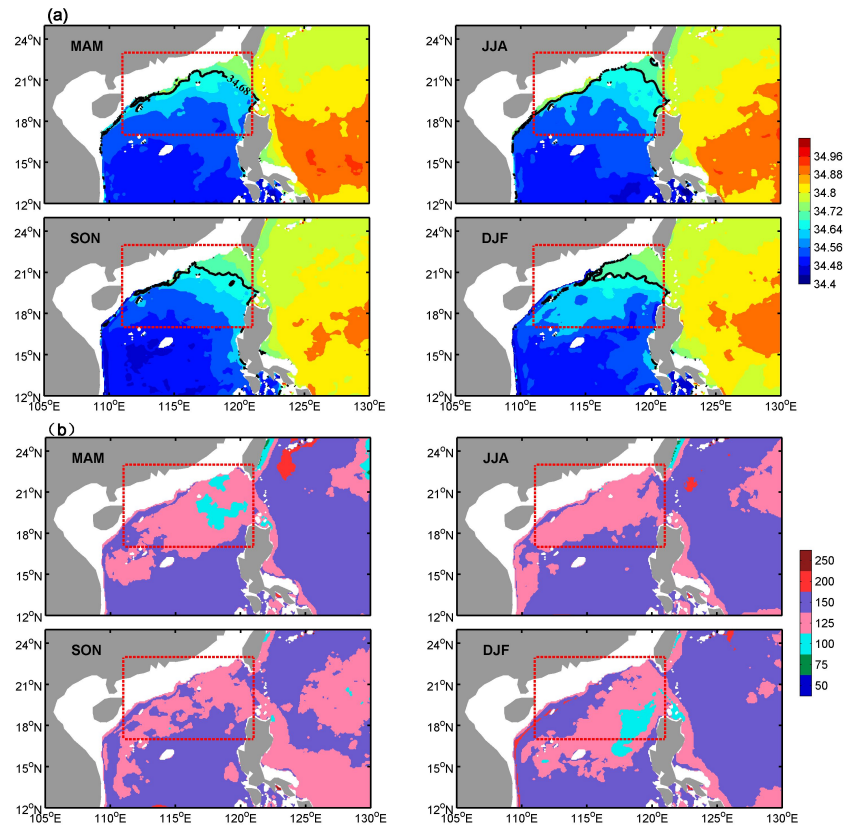

Figure 3. Seasonal variation of (a) the salinity maximum (shaded; PSU) and (b) depth (shaded; $m$ ) between 23.5 and $25.5 \sigma \theta$ in the SCS. Black contours represent 34.68 PSU and the red dotted box is our computation domain.

\section{Results}

\subsection{Spatial distribution and seasonal variation}

The spatial pattern of the SHSW in the northern SCS can be illustrated well by the subsurface salinity maximum $(\mathrm{Qu}$ et al., 1999). Figure 1 shows that the subsurface salinity maximum water spreads westward along the NEC and extends meridionally when it encounters the Philippines coast. Some of the water migrates northward with the Kuroshio and part of it flows further into the SCS across the LS. Along this spreading pathway from the NEC region to the northern SCS, the salinity maximum decreases gradually. The potential density at the salinity maximum depth increases from within the range of $23-25 \sigma_{\theta}$ to the range of $23.5-25.5 \sigma_{\theta}$ (Fig. 2). In this study, the subsurface salinity maximum in the northern SCS 


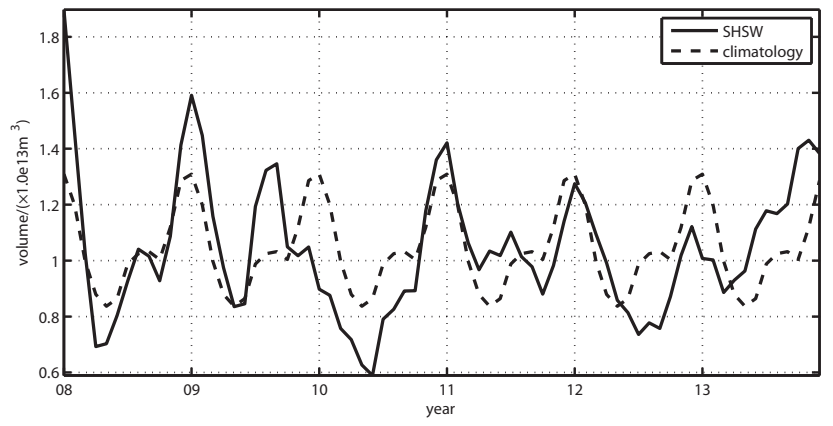

Figure 4. The monthly subsurface high-salinity water (SHSW) and the seasonal climatology of the SHSW in the northern SCS. SHSW is defined with the water salinity higher than 34.68 PSU at 111$121^{\circ} \mathrm{E}, 17-23^{\circ} \mathrm{N}$ between 23.5 and $25.5 \sigma \theta$. A 3-month running mean filter has been applied to remove high-frequency variations.

is restricted between the 23.5 and $25.5 \sigma_{\theta}$ layers, and we use the density range of $23.5-25.5 \sigma_{\theta}$ to search for SHSW. The vertical depth of the subsurface salinity maximum is defined as the layer with a zero diapycnal salinity gradient between 23.5 and $25.5 \sigma \theta$. Figure 3 describes the horizontal distributions of seasonal mean SHSW and their vertical depth in the study region. It is clearly seen that the maximum salinity in the western Pacific and the SCS is located between 125 and $150 \mathrm{~m}$. The maximum salinity is largest in the western Pacific, and its value is larger in the northern SCS basin than in the southern SCS basin, reflecting the fact that high-salinity water in the subsurface layer of the western Pacific intrudes into the SCS through the LS and then mixes with the local fresher water. Moreover, the SHSW in the northern SCS shows obvious seasonal variability. The scopes of the high salinity in autumn and winter are larger than those in spring and summer. In order to further investigate the seasonal variations of the SHSW in the northern SCS, we calculate the volume of the sea water salinity larger than 34.68 PSU between 23.5 and $25.5 \sigma_{\theta}$ within the dashed rectangle in Fig. 3. As shown in Fig. 4, the volume of the high-salinity water is highest in January and lowest in May. The seasonal variance contribution (seasonal variance accounting for the entire variance) is 0.38 . We have calculated seasonal variation of the subsurface salinity budget (figure not shown). The advection term mostly accounts for the contribution of the salinity tendency. This indicates that the advection through the LS may play an important role in the intrusion of the SHSW. Since the intrusion through the LS is affected by other factors, such as the large-scale forcing of the Pacific and the strength of the Kuroshio (Yaremchuk and Qu, 2004), the relationship between the NEC and the SHSW in the northern SCS becomes an interesting question.

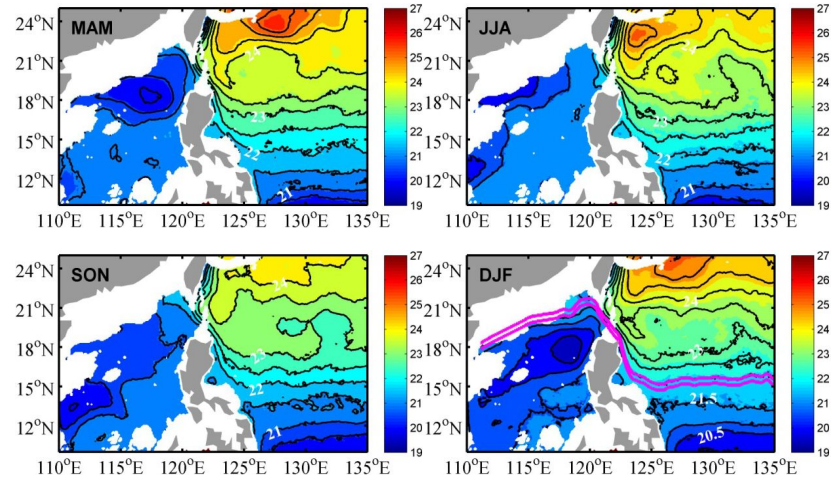

Figure 5. Seasonal acceleration potential $\left(\mathrm{m}^{2} \mathrm{~s}^{-2}\right)$ averaged between 23.5 and $25.5 \sigma_{\theta}$.

\subsection{Impact of the North Equatorial Current-Kuroshio circulation system}

Upper ocean circulation in the northwestern Pacific is mainly driven by the large-scale wind. The NEC between the 10 and $20^{\circ} \mathrm{N}$ bands is a stable westward current driven by wind and buoyancy flux. It splits into the poleward Kuroshio and the equatorward Mindanao Current (Nitani, 1972; Toole et al., 1990) when it encounters the coast of the Philippines, forming the so-called NEC-Mindanao Current-Kuroshio (NMK) circulation system (Qiu and Lukas, 1996). Influenced by monsoons and tropical coupled ocean-atmosphere dynamic processes, the NMK circulation system displays pronounced seasonal and interannual signals (Kim et al., 2004; Yan et al., 2014). The NEC bifurcation plays an important role in regulating the partition of mass and heat in the low-latitude western boundary (Chen, 2012; Yaremchuk and Qu, 2004). The northward-flowing Kuroshio partly intrudes into the SCS due to losing coastal support when it goes by the LS, then flows southwestward along the southern continental slope of China. It is obvious in Fig. 5 that the intrusion from the western Pacific into the SCS mainly occurs in autumn and winter. Especially in winter, the strong flow intrusion along the northern SCS continental slope can reach the western SCS. In summer, however, there is no significant Kuroshio intrusion and the SCS water even tends to flow back to the western Pacific to the southeast of Taiwan. The above seasonal features are basically consistent with Qu et al. (2004). For the annual mean state, the Kuroshio in the subsurface layer is a "leaping" pattern across the LS, though there is a small loop at about $21^{\circ} \mathrm{N}$ (Fig. 6).

In order to show the vertical structure of the SHSW along the Kuroshio, we draw the seasonal mean vertical salinity profiles (Fig. 7) along the pink band in Fig. 5d. In all four seasons, the high-salinity centers (greater than 34.68 PSU) exist at the depth of 100-300 $\mathrm{m}$ in the western Pacific, but shallow to about $80-200 \mathrm{~m}$ in the northern SCS. The lifting of isohalines and isopycnals occurs in the vicinity of $122^{\circ} \mathrm{E}$, which is attributed by some previous works to the warmer water in 


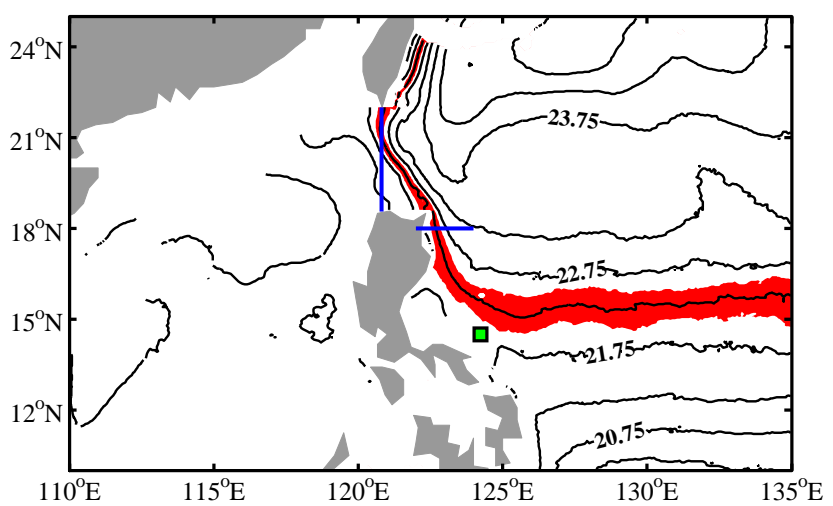

Figure 6. Same as Fig. 5 except for the annual average (contours). The red stripe represents the pathway of the North Equatorial Current-Kuroshio circulation system. The green box indicates the location of the mean NEC bifurcation. The two blue lines indicate the transects for computing Kuroshio transport (KT) and Luzon Strait transport (LST), respectively.

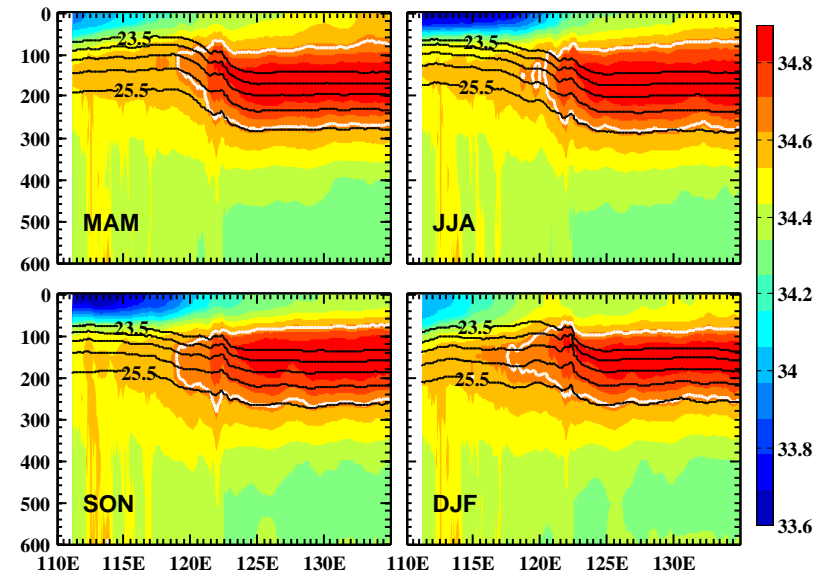

Figure 7. Salinity (color shading; PSU) and potential density (black contours; $\mathrm{kg} \mathrm{m}^{-3}$ ) along the flow in pink in Fig. 5. The white contours represent the 34.68 PSU salinity.

the western Pacific or the deep upwelling in the SCS (Nitani, 1972; Chao et al., 1996; Qu et al., 2000). But, Fig. 3b shows that the shallow SHSW extends from the eastern coast of Luzon into the northern SCS. It suggests the direct intrusion of SHSW from the left flank of the Kuroshio into the SCS, since beneath the strong northward Kuroshio, the isopycnals must tilt up westward under geostrophic balance. During autumnwinter, the SHSW can extend westward from the Pacific to about $116^{\circ} \mathrm{E}$ in the SCS. In summer, by contrast, the SHSW is confined to east of about $120^{\circ} \mathrm{E}$, and there exists a highsalinity water patch west of $120^{\circ} \mathrm{E}$, probably due to the activity of mesoscale eddies.

Figure 8 shows the seasonal-average salinity and zonal current velocity at $120.8^{\circ} \mathrm{E}$ (position shown in Fig. 6). It can be seen that, in all four seasons, the westward inflow through
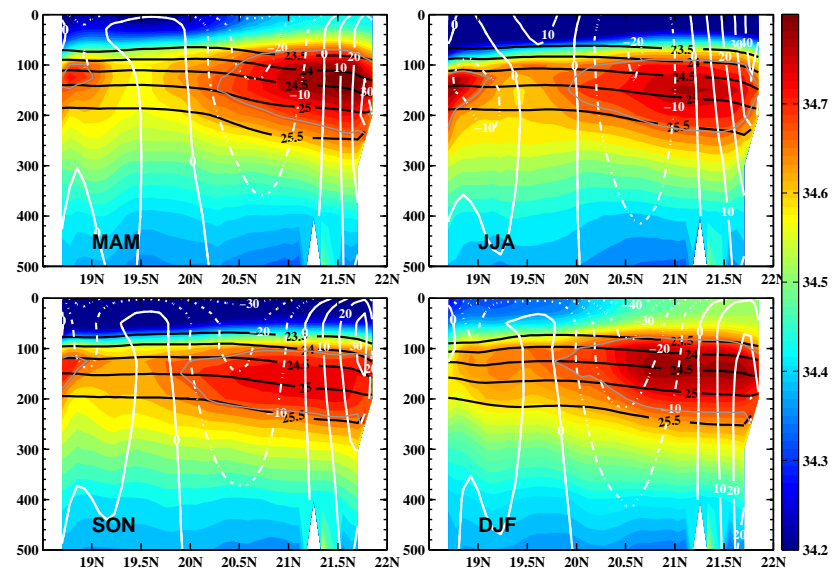

Figure 8. Seasonal salinity (color shading; PSU) and zonal velocity (white contours; $\mathrm{cm} \mathrm{s}^{-1}$ ) along the Luzon Strait $\left(120.8^{\circ} \mathrm{E}\right)$. Black lines represent the potential density. Grey contours indicate 34.68 PSU salinity. Positive (negative) values represent eastward (westward) currents. The contour interval of zonal velocity is $10 \mathrm{~cm} \mathrm{~s}^{-1}$.

the LS is mainly confined to the upper $400 \mathrm{~m}$ between 20 and $21.3^{\circ} \mathrm{N}$. While the outflow from the SCS to the western Pacific mainly occurs south of $20^{\circ} \mathrm{N}$ and north of $21.3^{\circ} \mathrm{N}$, the inflow is relatively broader than the outflow and there exists significant seasonal variability that in winter is strongest and in summer is weakest. In the LS, the salinity maximum is mainly confined between 23.5 and $25.5 \sigma_{\theta}$ and the center of the SHSW is located at the boundary of the westward inflow and the eastward outflow. Its magnitude reaches the maximum in winter and the minimum in summer.

Considering that the North Equatorial Current bifurcation latitude (NECBL) is an important indicator that influences the low-latitude western Pacific current system, we further discuss the correlations between the variabilities of the NECBL, the Kuroshio, and the SHSW in the northern SCS. In this study, the bifurcation latitude is obtained where the subsurface averaged meridional velocity is zero in the $2^{\circ}$ band east of the Philippines coast (Qiu and Chen, 2010). Under linear wind-driven Sverdrup approximation theory, the NECBL occurs at the zero zonally integrated line of the northern Pacific wind stress curl (about $14.6^{\circ} \mathrm{N}$ in the climatological average) (Qu and Lukas, 2003). The wind-driven baroclinic Rossby wave plays a key role in the variations of the bifurcation latitude (Qiu and Chen, 2010). The NECBL in the HYCOM simulation shows an obvious annual cycle with the annual mean latitude of $14.2^{\circ} \mathrm{N}$. The NECBL reaches its southernmost point (about $13.6^{\circ} \mathrm{N}$ ) in June and its northernmost point $\left(14.7^{\circ} \mathrm{N}\right)$ in December, which is basically consistent with many previous studies (e.g., Wang and $\mathrm{Hu}, 2006$; Chen, 2012). In all these studies (Table 1), the seasonal phase changes of NECBL are similar, but the locations of NECBL show large diversities due to their differences in the computation depths and NECBL definitions. As the NECBL shifts 
Table 1. Seasonal variation of NECBL by different studies.

\begin{tabular}{|c|c|c|}
\hline & $\begin{array}{l}\text { Southernmost } \\
\text { time-location(depth) }\end{array}$ & $\begin{array}{l}\text { Northernmost } \\
\text { time-location(depth) }\end{array}$ \\
\hline Qu and Lukas, 2003 & July $-14.8 \mathrm{~N}(0-1000 \mathrm{~m})$ & December - $17.2 \mathrm{~N}(0-1000 \mathrm{~m})$ \\
\hline Kim et al., 2004 & July - 15.1 N (500 m) & January - $18 \mathrm{~N}(500 \mathrm{~m})$ \\
\hline Wang and $\mathrm{Hu}, 2006$ & June $-12.9 \mathrm{~N}$ (surface) & December - $14.1 \mathrm{~N}$ (surface) \\
\hline Qiu and Chen, 2010 & June $-11.6 \mathrm{~N}$ (surface) & December - $12.5 \mathrm{~N}$ (surface) \\
\hline Chen and $\mathrm{Wu}, 2011$ & June $-13.7 \mathrm{~N}(0-400 \mathrm{~m})$ & November - $16 \mathrm{~N}(0-400 \mathrm{~m})$ \\
\hline Present paper & May $-13.1 \mathrm{~N}\left(23.5-25.5 \sigma_{\theta}\right)$ & December $-14.4 \mathrm{~N}\left(23.5-25.5 \sigma_{\theta}\right)$ \\
\hline
\end{tabular}

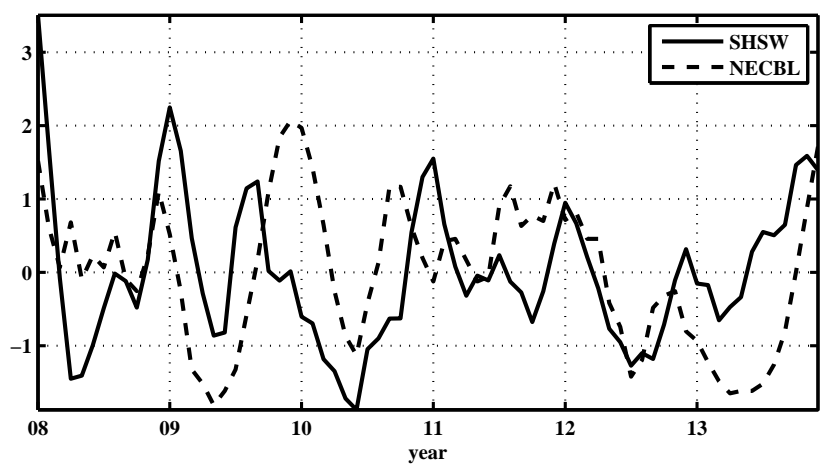

Figure 9. Seasonal variation of the subsurface high-salinity water (SHSW) in the northern SCS and the NEC bifurcation latitude (NECBL) (all normalized after applying a 3-month smoothing average). The correlation coefficient between them is 0.27 (98\% confidence).

northward with increasing depth (e.g., Qu and Lukas, 2003), the subsurface NECBL in our work is more northward than surface NECBL (Wang and Hu, 2006; Qiu and Chen, 2010) and more southward than the deeper one $(\mathrm{Qu}$ and Lukas, 2003; Kim et al., 2004). The above comparison also verified that our method to define the NECBL is feasible and that the data we used are credible.

The normalized seasonal time series of the NECBL, the Kuroshio transport (KT), the Luzon Strait transport (LST), and the SHSW are shown in Fig. 10. The locations for computing the KT and LST are denoted in Fig. 6. In this study, the $\mathrm{KT}$ is defined as the transport across the $18^{\circ} \mathrm{N}$ transect from the eastern coast of Luzon to $124^{\circ} \mathrm{E}$ within the 23.5 and $25.5 \sigma_{\theta}$ layers; the KT reaches the minimum in October and the maximum in February. Generally, the seasonal variation of the NECBL leads the KT by 3 months (correlation coefficient is 0.97). The phase lag between KT and NECBL is probably due to the modulations of eddy activities.

The LST across the $120.8^{\circ} \mathrm{E}$ section within the 23.5$25.5 \sigma_{\theta}$ layers displays similar seasonal variability to the NECBL. It reaches the minimum $(0.59 \mathrm{~Sv})$ in July and the maximum $(2.13 \mathrm{~Sv})$ in January, lagging the seasonality of NECBL by 1 month. Previous studies considered the fact that the change in the LST is closely related to the Kuroshio in-

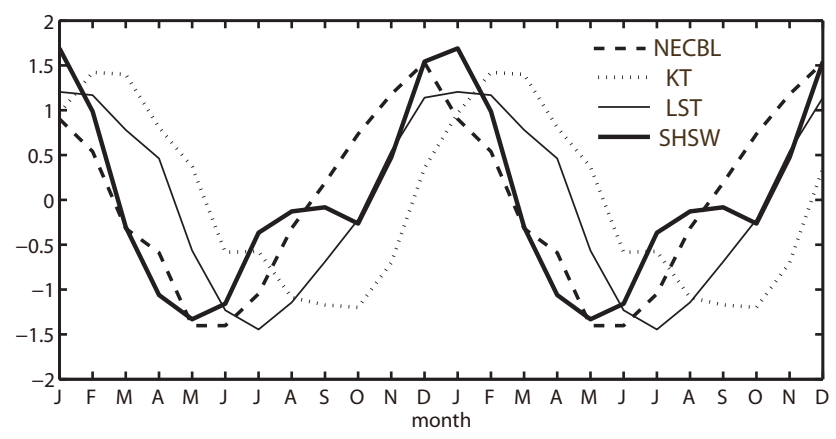

Figure 10. Seasonal variation of the NEC bifurcation latitude (NECBL), the Kuroshio transport (KT), the Luzon Strait transport (LST), and the subsurface high-salinity water (SHSW) in the northern SCS (all normalized after applying a 3-month running mean filter; all time series computed in subsurface layers between 23.5 and 25.5 potential density).

tensity east of Luzon (Wang et al., 1997; Sheu et al., 2010), which was explained by Yaremchuk and Qu (2004) by using the inertia effect of the western boundary current. However, the result of HYCOM data shows that, although the seasonal variation of the LST is highly correlated with that of the NECBL (0.70), its contemporary correlation with the $\mathrm{KT}$ is pretty low (Fig. 10), which means that the changes in the Kuroshio intensity may not be the most important factor that controls the LST. Recent studies showed that when the westward baroclinic Rossby waves in the tropical Pacific impinge on the eastern Philippines coast, they excite coastal Kelvin waves, which propagate through the Mindoro Strait into the eastern SCS, modulate the sea level south of the Luzon Strait, and thus influence the LST (e.g., Liu et al., 2011; Zhuang et al., 2013). This dynamic process may be important for the water exchange and high-salinity water intrusion through the LS.

\section{Summary and discussion}

This paper analyzes the distribution and seasonal variability of the SHSW in the northern SCS based on the highresolution HYCOM assimilation product from 2008 to 2013. 
The modeling results show that, during this period, the northern SCS SHSW is mainly located between 80 and $200 \mathrm{~m}$ in depth and displays a pronounced seasonal cycle. The volume of SHSW reaches its minimum in May and maximum in January. Further research shows that the seasonality of SHSW in the SCS is mainly influenced by the intrusion of the western Pacific NPTW through the LS at around $20-21.3^{\circ} \mathrm{N}$ between 23.5 and 25.5 potential density, and the core of the SHSW lies on the boundary of the westward inflow and the eastward outflow. Part of the high-salinity water flows back into the western Pacific through $21.3-22^{\circ} \mathrm{N}$ of the LS. The LST and salinity flux is closely correlated with the western Pacific large-scale circulation, especially the NECBL, which shifts northernmost in December, and southernmost in May. It indicates that the changes in western Pacific large-scale circulation modulate the water exchange in the LS, and thus influence the SHSW in the interior SCS basin.

It is noteworthy that the variability of the Kuroshio transport is not exactly in phase with the NECBL and LST, probably due to the modulation of eddy activities. It means that the Kuroshio transport east of the LS is not the only factor that controls the LST. Recent studies noted another dynamic process about the impacts of Pacific on the SCS (Liu et al., 2011; Zhuang et al., 2013). When wind-driven baroclinic Rossby waves in the tropical western Pacific propagate westward and reach the eastern Philippines coast, they can excite coastal Kelvin waves. The coastal Kelvin waves propagate into the eastern SCS through the Sibutu Strait and Mindoro Strait, thus influencing the sea level south of the LS and the transport across the strait. Due to complex dynamic processes in the northern SCS, the mechanisms of the SHSW changes are complicated. In addition to the impacts of the large-scale circulations, the contribution from mesoscale eddies and local wind also needs further studies in the future.

Acknowledgements. We thank Ruixin Huang for useful advice and comments. This research was supported by the Strategic Priority Research Program of the Chinese Academy of Sciences (XDA11010103), the National Basic Research Program of China (2010CB950302), the National Natural Science Foundation of China (projects 41176024 and 41176028) and the CAS/SAFEA International Partnership Program for Creative Research Teams. We would like to acknowledge the National Ocean Partnership Program (NOPP) for providing the high-resolution HYCOM data (http://hycom.org/dataserver/). The MIMOC product was provided by NASA (http://www.pmel.noaa.gov/mimoc/). The WOA01 was obtained from the Ocean Climate Laboratory, NODC (http://www.nodc.noaa.gov/OC5/WOA01/woa01dat.html).

Edited by: A. J. G. Nurser

\section{References}

Centurioni, L. R., Niiter, P. P., and Lee, D. K.: Observations of inflow of Philippine Sea surface water into the South China Sea through the Luzon Strait, J. Phys. Oceanogr., 34, 113-121, 2004.

Chao, S.-Y., Shaw, P. T., and Wu, S. Y.: Deep sea ventilation in the South China Sea, Deep-Sea Res. Pt. I, 43, 445-466, 1996.

Chen, Z. H.: Study on the multi time scale variability and dynamics of the North Equatorial Current Bifurcation in the Pacific, Ph.D. thesis, Ocean University of China, Qingdao, 114 pp., 2012 (in Chinese).

Chen, Z. and Wu, L.: Dynamics of the seasonal variation of the North Equatorial Current bifurcation, J. Geophys. Res., 19782012, 116, 2011.

Farris, A. and Wimbush, M.: Wind-induced Kuroshio intrusion into the South China Sea, J. Oceanogr., 52, 771-784, 1996.

Gordon, A. L., Huber, B. A., Metzger, E. J., Susanto, R. D., Hurlburt, H. E., and Adi, T. R.: South China Sea throughflow impact on the Indonesian throughflow, Geophys. Res. Lett., 39, L11602, 2012.

Kim, Y. Y., Qu, T., Jensen, T., Miyama, T., Mitsudera, H., Kang, H.-W., and Ishida, A.: Seasonal and interannual variations of the North Equatorial Current bifurcation in a high-resolution OGCM, J. Geophys. Res., 109, C03040, doi:10.1029/2003JC002013, 2004.

Li, L., Nowlin, W. D., and Su, J. L.: Anticyclonic rings from the Kuroshio in the South China Sea, Deep-Sea Res. Pt. I, 45, 1469 1482, 1998.

Li, W. and Liu, Q. Y.: A preliminary study of the deformation and its dynamics of western boundary current at a gap, Journal of Ocean University of Qingdao, 27, 277-281, 1997 (in Chinese).

Li, W., Liu, Q. Y., and Cheng, S.-P.: The effect of break in western boundary on the western boundary current, Acta Oceanographica Taiwanica, 35, 141-153, 1996.

Li, Y. L. and Wang, F.: Spreading and salinity change of North Pacific Tropical Water in the Philippine Sea, J. Oceanogr., 68, 439452, 2012.

Liu, Q. Y., Feng, M., and Wang, D. X.: ENSO-induced interannual variability in the southeastern South China Sea, J. Oceanogr., 67, 127-133, 2011.

Liu, Y., Bye, J. A., You, Y., Bao, X., and Wu, D.: The flushing and exchange of the South China Sea derived from salt and mass conservation, Deep-Sea Res. Pt. II, 57, 1212-1220, 2010.

Metzger, E. J. and Hurlburt, H. E.: Coupled dynamics of the South China sea, the Sulu sea, and the Pacific ocean, J. Geophys. Res.Oceans, 101, 12331-12352, 1996.

Montgomery, R. B. and Stroup, E. D.: Equatorial Waters and Currents at $150^{\circ} \mathrm{W}$ in July-August 1952: Tome 1, 1962.

Nitani, H.: Beginning of the Kuroshio, in: Kuroshio: Its Physical Aspects, edited by: Stommel, H. and Yoshida, K., University of Tokyo Press, Tokyo, 129-163, 1972.

Pu, S. Z., Yu, H. L., and Jiang, S. N.: Branchings of Kuroshio into Bashi Channel and South China Sea, Tropic Oceanology, 11, 18, 1992 (in Chinese).

$\mathrm{Pu}$, S. Z., Yu, H. L., and Jiang, S. N.: The upper layer circulation in the Bashi Channel and the northeastern South China Sea, in: Proceedings of the Symposium on the Physical and Chemical Oceanography of the China Seas, China Ocean Press, Beijing, 10-18, 1993. 
Qiu, B. and Chen, S.: Interannual-to-decadal variability in the bifurcation of the north equatorial current off the Philippines, J. Phys. Oceanogr., 40, 2525-2538, 2010.

Qiu, B. and Lukas, R.: Seasonal and interannual variability of the North Equatorial Current, the Mindanao Current, and the Kuroshio along the Pacific western boundary, J. Geophys. Res., 101, 12315-12330, 1996.

$\mathrm{Qu}, \mathrm{T}$. and Lukas, R.: The bifurcation of the north equatorial current in the Pacific, J. Phys. Oceanogr., 33, 5-18, 2003.

Qu, T., Mitsudera, H., and Yamagata, T.: A climatology of the circulation and water mass distribution near the Philippine coast*, J. Phys. Oceanogr., 29, 1488-1505, 1999.

Qu, T., Mitsudera, H., and Yamagata, T.: Intrusion of the North Pacific waters into the South China Sea, J. Geophys. Res.-Oceans, 105, 6415-6424, 2000.

Qu, T., Kim, Y. Y., Yaremchuk, M., Tozuka, T., Ishida, A., and Yamagata, T.: Can Luzon strait transport play a role in conveying the impact of ENSO to the South China Sea?, J. Climate, 17, 3644-3657, 2004.

Reid Jr., J. L.: Intermediate waters of the Pacific Ocean (No. JHU), Scripps Institution of Oceanography, La Jolla, CA, 1965.

Shaw, P. T.: The seasonal variation of the intrusion of the Philippine Sea water into the South China Sea, J. Geophys. Res.-Oceans, 96, 821-827, 1991.

Shaw, P. T. and Chao, S. Y.: Surface circulation in the South China Sea, Deep-Sea Res. Pt. I, 41, 1663-1683, 1994.

Sheu, W. J., Wu, C. R., and Oey, L. Y.: Blocking and westward passage of eddies in the Luzon Strait, Deep-Sea Res. Pt. II, 57, 1783-1791, 2010.

Schmidtko, S., Johnson, G. C., and Lyman, J. M.: MIMOC: a global monthly isopycnal upper-ocean climatology with mixed layers, J. Geophys. Res., 118, 1658-1672, doi:10.1002/jgrc.20122, 2013.

$\mathrm{Su}$, J. L.: A review of circulation dynamics of the coastal oceans near China, Acta Oceanol. Sin., 23, 1-16, 2001.

Tian, J., Yang, Q., Liang, X., Xie, L., Hu, D., Wang, F., and Qu, T.: Observation of Luzon Strait transport, Geophys. Res. Lett., 33, L19607, doi:10.1029/2006GL026272, 2006.

Toole, J. M., Millard, R. C., Wang, Z., and Pu, S.: Observations of the Pacific North Equatorial Current bifurcation at the Philippine coast, J. Phys. Oceanogr., 20, 307-318, 1990.

Wang, D., Liu, Q., Huang, R. X., Du, Y., and Qu, T.: Interannual variability of the South China Sea throughflow inferred from wind data and an ocean data assimilation product, Geophys. Res. Lett., 33, L14605, doi:10.1029/2006GL026316, 2006.
Wang, J. and Chern, C. S.: Some aspects on the circulation in the northern South China Sea, La Mer, 34, 246-257, 1996.

Wang, J. and Chern, C. S.: On the trajectory of subsurface and intermediate waters in the northeastern South China Sea, J. Tropic. Oceanogr., 16, 24-41, 1997 (in Chinese).

Wang, Q. and Hu, D.: Bifurcation of the North Equatorial Current derived from altimetry in the Pacific Ocean, J. Hydrodynamics, Ser. B, 18, 620-626, 2006.

Wyrtki, K.: Physical Oceangraphy of the Southeast Asian Waters, The University of California Scripps Institution of Oceanography, La Jolla, CA, 1961.

$\mathrm{Xu}$, J. P. and Su, J. L.: Hydrographic analysis on the intrusion of the Kuroshio into the South China Sea II. Observational results during the cruise from August to September in 1994, Journal of Tropical Oceanography, 16, 1-23, 1997 (in Chinese).

Yan, Q., Hu, D., and Zhai, F.: Seasonal variability of the North Equatorial Current transport in the western Pacific Ocean, Chinese journal of oceanology and limnology, 32, 223-237, 2014.

Yaremchuk, M. and Qu, T.: Seasonal variability of the largescale currents near the coast of the Philippines coast, J. Phys. Oceanogr., 34, 844-855, 2004.

Yuan, D., Han, W., and Hu, D.: Surface Kuroshio path in the Luzon Strait area derived from satellite remote sensing data, J. Geophys. Res.-Oceans, 111, 2006.

Yuan, Y., Tseng, Y. H., Yang, C., Liao, G., Chow, C. H., Liu, Z., Zhu, X., and Chen, H.: Variation in the Kuroshio intrusion: modeling and interpretation of observations collected around the Luzon Strait from July 2009 to March 2011, J. Geophys. Res., 119, 3447-3463, 2014.

Zhang, Y. H. and Du, Y.: Seasonal variability of salinity budget and water exchange in the northern Indian Ocean from HYCOM assimilation, Chin. J. Oceanol. Limn., 30, 1082-1092, 2012.

Zhang, Z., Zhao, W., and Liu, Q.: Sub-seasonal variability of Luzon strait transport in a high resolution global model, Acta Oceanol. Sin., 29, 9-17, 2010.

Zhuang, W., Qiu, B., and Du, Y.: Low-frequency Western Pacific Ocean sea level and circulation changes due to the connectivity of the Philippine archipelago, J. Geophys. Res.-Oceans, 118, 6759-6773, 2013. 